\title{
Editorial: How to get your manuscript accepted
}

\author{
Kristian Daneback ${ }^{1}$, Lenka Dedkova², David Smahel ${ }^{3}$ \\ ${ }^{1}$ Department of Social Work, University of Gothenburg, Gothenburg, Sweden \\ ${ }^{2,3}$ Faculty of Social Studies, Masaryk University, Brno, Czech Republic
}

Dear researchers, colleagues, and readers interested in internet-related research,

We are delighted to present the fourth and final issue of 2016, which comprises of seven articles that cover a variety of topics, theoretical perspectives, and methodological approaches. Besides an article from the U.S., the research presented in this issue is primarily conducted by researchers in Europe. What we especially like to see is the international collaborations between researchers across nations - one of the studies, for example, brings together researchers from Norway, Germany, and the Netherlands. As internet researchers, we sometimes find ourselves alone in our departments, either because of being sort of aliens in relation to our academic discipline or because we run out of funding and have to dissolve our groups. Combining perspectives across disciplines and nations are, of course, other sound reasons for collaboration. Therefore, finding and/or inviting colleagues internationally may keep us in business and able to continue to investigate the different corners of cyberspace in the most fruitful ways.

We already published an editorial to reveal the most frequent reasons for direct rejections in our journal, including the issues to avoid when submitting a manuscript. In this issue, we would like to present the reasons why we like to accept articles for publication. Please do not perceive the following list of "best practices" as exhaustive, but we hope it might help you to improve your future contributions:

Title. It should be informative and accurate, and reflect the focus of the article. However, a too long and detailed title is not always the answer, nor is a too broad and general title.

Strong abstract. Besides the title, the abstract is the very first coherent part of the manuscript that readers go through to decide if they want to continue reading the article or not. This is quite obvious. Perhaps not so often mentioned and considered, this is also the first part that editors and reviewers read. In many journals, this is the part that - when poorly written - can send your article to direct rejection without even a look at the other parts of the manuscript. This applies to reviewers as well - based on the abstract, they decide to review it or to politely decline. A well-written abstract has to include all the information that editors/reviewers/readers need to know: a) what was done in the study; b) how was it done (on what sample, with what methods); and c) what are the main findings. At the same time, it is important to not promise more than what was actually done - you have to arouse the reader's curiosity so that they will be motivated to read/review the piece, but you do not want to raise unreasonable expectations that would inevitably lead to disappointing your reader and reviewer. Granted, it requires certain skills to find the correct balance and include all of the important information in a limited space. The energy put into the abstract, however, pays off, and we would like to underscore how important it is to dedicate enough time to write it. 
Clear contribution and justification of the study. This probably goes without saying: articles that are accepted provide new knowledge and insights into the field. The inevitable, important, and yet often-neglected, part of this point is the clear justification of the study and the explicit identification of its contribution (while, of course, admitting its limitations). Too often, we have read (and rejected) manuscripts without ever learning why the study was important to conduct in the first place. Needless to say, it is absolutely not sufficient to merely state that such a study was never done before; if this is really the sole reason, the study might be meaningless and reviewers and editors are very careful about this.

Methods. The chosen method(s) should be appropriate for the researched problem, they should be clearly described, and they should be in line with the APA manual. This is a very basic requirement and it is fine to do "just" this (though sometimes it is quite challenging), but what we like in particular are innovative methods that push the horizons and may lead to really new findings. Of course, even innovative methods have to be appropriate, justified, and clearly described.

Discussion and conclusions. A discussion is not a repetition of the results; it is the results discussed in relation to theory and prior research. This is where findings should be supported or contradict what is already known. The conclusion should be short and clearly state the main finding, its implication, and possibly the way forward. What did you find and why is it important? Write explicitly why your study is important and what your contributions are to the current field of art. It is always a pleasure to read a discussion that offers the reader new (yet appropriate) perspectives on the matter, and one that it is apparent that the authors really thought about the studied issues in depth.

The article is telling a good story. This is a lot about the meaningful structure and the authors' skills to present the right piece of information at just the right time to have a fluent, clearly written, and easy-to-understand manuscript. The APA manual can help a lot with the structure. The paragraphs should be interconnected, the readers should understand (and ideally resonate) with the logic behind the manuscript, and they should feel that nothing important is missing. A typical example of a fluency-destroyer that we have seen in many, often beginner, manuscripts, is providing too many results, which makes the article incomprehensible.

Language. Strongly connected to the previous point, the language in the article is an important aspect that makes telling a story either easier or harder. For those whose native language is not English, this can be a big barrier to a great article.

Disposition. A manuscript is comprised of three parts: A beginning, a middle, and an ending. These three parts should be in balance. Sometimes we receive manuscripts with too much of one or two parts. Find the balance!

The article follows APA guidelines. Experienced editors can see at first glance when the article is not in line with the journal guidelines. Such a problem causes the editor to reject the article.

As you can see, a lot is about experience and finding the right balance in all parts of the article. Just like in any other area, practice makes perfect - but no matter if you are a beginner or already experienced as an author, it is always a good idea to give the article to someone else to read before submitting it to the journal. An outsider can point out weaknesses that the authors, immersed in their manuscript, may fail to see but that will definitely be noticed by editors and reviewers.

As noted, this list is not exhaustive, but if you fulfill all of the conditions described above, you are well on the way to a high quality article.

Before we proceed to the content of the current issue, we are excited to share one piece of good news: we recently learned that Cyberpsychology will be covered in the "Emerging Sources Citation Index". This means that the articles published since the beginning of 2016 will be indexed in the Web of Science. This is great progress for the journal and we are very proud to be included in this prestigious database. 
Now to the content of the current issue.

The first article in this issue is "Who is really British anyway? - A thematic analysis of responses to online hate materials" (Rohlfing, Sonnenberg). It focuses on the responses to a racist video clip. The authors find that there is a variety of responses, from endorsing the racist content to challenging it. This leads to the conclusion that online hate material does not automatically generate online hate responses.

In the second article - "Informational benefits from social media use for professional purposes: Results from a longitudinal study" (Utz, Breuer) - work-related benefits, such as job suggestions due to social media visibility, are investigated. The authors found that the number and strength of ties associated with information is beneficial, but that there is also complex interplay between parallel and longitudinal processes.

The third article - "Developing a shorter version of the Estonian Smartphone Addiction Proneness Scale (ESAPS18)" (Rozgonjuk, Rosenvald, Janno, Täht) - aims to refine and validate an instrument that measures smartphone addiction. Almost 800 respondents participated in the study and the authors concluded that the previous 33-item scale could be shortened to 18. In addition, they suggested that the underlying mechanisms were similar to other internet-related addictions.

In the fourth article - "The use of digital technology in substance misuse recovery" (Dugdale, Elison, Davies, Ward, Jones) - investigated the available resources for treatment and recovery from substance misuse. Through a mixed-method design, the authors found that online forums were the most popular resource, but that it shifts depending on the stages and needs in the recovery process. They also found an interaction between online and offline resources, but lack the signposting to appropriate recovery and treatment recourses.

The fifth article - "Help-giving and moral courage on the Internet" (Kinnunen, Lindeman, Verkasalo) - examined two types of prosocial behavior on the internet. Based on the Big Five personality traits, they found, for example, that an open personality and high weekly use of social media was associated with a willingness to help on the internet. Sadistic traits, normally considered undesirable, may in fact be beneficial and have positive outcomes on the internet.

The sixth article - "Privacy cynicism: A new approach to the privacy paradox" (Hoffmann, Lutz, Ranzini) - draws upon a literature review to define the concept of privacy and then conduct an empirical qualitative study to substantiate the theoretical concept. The result is the concept of privacy cynicism, which means that feelings of mistrust, powerlessness, and public vulnerability may negatively influence privacy behavior and attitudes online.

The seventh study is : "Anonymously male: Social media avatar icons are implicitly male and resistant to change" (Bailey, LaFrance). By using avatars commonly seen on high traffic websites, participants were exposed to a neutral and a more female type, and respondents were asked to indicate the gender of the avatar. They found that even in seemingly gender-neutral online contexts, male-centric thinking is evident. In addition, a conservative political stance had an impact on producing an avatar as typically male.

Finally, as 2016 is coming to an end, we would like to thank all of the contributors and reviewers who have shared their time and efforts to make this another successful year in the history of the journal. We would like to wish you a wonderful holiday season and a happy new year!

All the best,

Kristian Daneback, Lenka Dedkova, and David Smahel 


\section{Issue Content}

Article 1:

Editorial: How to get your manuscript accepted

Kristian Daneback, Lenka Dedkova and David Smahel

doi: 10.5817/CP2016-4-1

Article 2:

"Who is really British anyway?": A thematic analysis of responses to online hate materials Sarah Rohlfing and Stefanie Sonnenberg

doi: 10.5817/CP2016-4-2

Article 3:

Informational benefits from social media use for professional purposes: Results from a longitudinal study

Sonja Utz and Johannes Breuer

doi: 10.5817/CP2016-4-3

Article 4:

Developing a shorter version of the Estonian Smartphone Addiction Proneness Scale (E-SAPS18)

Dmitri Rozgonjuk, Valdur Rosenvald, Sven Janno and Karin Täht

doi: 10.5817/CP2016-4-4

Article 5:

The use of digital technology in substance misuse recovery

Stephanie Dugdale, Sarah Elison, Glyn Davies, Jonathan Ward and Michaela Jones

doi: 10.5817/CP2016-4-5

Article 6:

Help-giving and moral courage on the Internet

Suna P. Kinnunen, Marjaana Lindeman and Markku Verkasalo

doi: 10.5817/CP2016-4-6

Article 7:

Privacy cynicism: A new approach to the privacy paradox

Christian Pieter Hoffmann, Christoph Lutz and Giulia Ranzini

doi: 10.5817/CP2016-4-7

Article 8:

Anonymously male: Social media avatar icons are implicitly male and resistant to change

April H. Bailey and Marianne LaFrance

doi: 10.5817/CP2016-4-8

\section{About Journal}

The 'Cyberpsychology: Journal of Psychosocial Research on Cyberspace' is a web-based, peer-reviewed scholarly journal. The first peer-reviewed issue was published in September 2007. The journal is focused on social science research about cyberspace. It brings psychosocial reflections of the impact of the Internet on people and society. The journal is interdisciplinary, publishing works written by scholars of psychology, media studies, communication science, sociology, political science, nursing, ICT security, organizational psychology and also other disciplines with relevance to psychosocial aspects of cyberspace. The journal accepts original research articles, as well as theoretical studies and research meta-analyses. Proposals for special issues are also welcomed. 
The journal is indexed with SCOPUS, ERIH PLUS, EBSCO Academic Search Complete, the Directory of Open Access Journals and the Czech Database of Scientific Journals.

\section{Editor}

Prof. David Smahel, M.Sc. et Ph.D., Faculty of Social Studies, Masaryk University, Czech Republic

E-mail: smahel(at)fss.muni.cz

\section{Associate Editor}

Prof. Kristian Daneback, Ph.D., University of Gothenburg, Sweden

E-mail: kristian.daneback(at)socwork.gu.se

\section{Managing Editor}

Lenka Dedkova, Ph.D., Faculty of Social Studies, Masaryk University, Czech Republic

E-mail: Idedkova(at)fss.muni.cz

\section{Editorial Board}

Prof. Kaveri Subrahmanyam, Ph.D., California State University, Los Angeles, USA

Prof. Herbert Hrachovec, Ph.D., University of Vienna, Austria

Prof. Dr. Micheline Frenette, Universite de Montreal, Canada

Prof. Alexander E. Voiskounsky, Ph.D., Lomonosov Moscow State University, Russia

Prof. Michael W. Ross, Ph.D., DrMedSc, MPH, MPHEd, University of Texas, Houston, USA

Prof. Petr Macek, CSc., Masaryk University, Czech Republic

Prof. Olle Findahl, World Internet Institute, Sweden

Prof. Jochen Peter, Ph.D., University of Amsterdam, Netherlands

Prof. Veronika Kalmus, Ph.D., University of Tartu, Estonia

Prof. Joshua Fogel, Ph.D., Brooklyn College of the City University of New York, USA

Prof. Gustavo S. Mesch, Ph.D., University of Haifa, Israel

Prof. Lelia Green, Ph.D., Edith Cowan University, Australia

Prof. Michel Walrave, Ph.D., University of Antwerp, Belgium

Michelle Wright, Ph.D., Masaryk University, Czech Republic

Václav Štětka, Ph.D., Charles University, Czech Republic

Andra Siibak, Ph.D., University of Tartu, Estonia

Adjunct Prof. Birgit U. Stetina, Ph.D., University of Vienna, Austria

Lukas Blinka, Ph.D., Masaryk University, Czech Republic

\section{Advisory Board}

Prof. Bente Traen, Ph.D., University of Oslo, Norway

Prof. Charles Ess, Ph.D., University of Oslo, Norway

Prof. Dr. Ilse Kryspin-Exner, University of Vienna, Austria

Prof. PhDr. Jan Jirák, Ph.D., Charles University, Czech Republic

Prof. Vasja Vehovar, Ph.D., University of Ljubljana, Slovenia

Prof. Larry D. Rosen, Ph.D., California State University, USA

Prof. Patricia M. Greenfield, Ph.D., University of California, USA

Prof. Peter K Smith, University of London, England

Prof. Nicola Döring, Ilmenau University of Technology, Germany

Prof. Kimberly Young, Ph.D., St. Bonaventure University, USA

Prof. Jos de Haan, Ph.D., Erasmus University, Netherlands

Prof. Zbyněk Vybíral, Ph.D, Masaryk University, Czech Republic 
Prof. Monica Whitty, Ph.D., University of Leicester, UK

Prof. Alistair Duff, Ph.D., Edinburgh Napier University, Scotland

Assoc. Prof. Alfred Choi, Ph.D., Nanyang Technological University, Singapore

Prof. Thurasamy Ramayah, Universiti Sains Malaysia, Malaysia

Assoc. Prof. Neil Coulson, Ph.D., The University of Nottingham, UK

Assoc. Prof. Kenneth C. C. Yang, Ph.D., University of Texas at El Paso, USA

Assoc. Prof. Sun Sun Lim, Ph.D., National University of Singapore, Singapore

Prof. Sameer Hinduja, Ph.D., Florida Atlantic University, USA

Assoc. Prof. Jana Horáková, Ph.D., Masaryk University, Czech Republic

Assoc. Prof. Radim Polčák, Ph.D., Masaryk University, Czech Republic

Assoc. Prof. Pille Pruulmann-Vengerfeldt, Ph.D., University of Tartu, Estonia

Assist. Prof. Alexander Schouten, Ph.D., Tilburg University, Netherlands

Assist. Prof. Ewa S. Callahan, Ph.D., Quinnipiac University, USA

Assist. Prof. Regina van den Eijnden, Ph.D., Utrecht University, Netherlands

PhDr. Ing. Petr Soukup, Charles University, Czech Republic

Janis Wolak, Ph.D., University of New Hampshire, USA

Francesca Romana Seganti, Ph.D., Sapienza University of Rome, Italy

Jeff Gavin, Ph.D., University of Bath, UK

Hana Macháčková, Ph.D., Masaryk University, Czech Republic

Michael Fenichel, Ph.D., New York, USA

Leslie Haddon, Ph.D., London School of Economics, UK

\section{Publisher}

Masaryk University, Faculty of Social Studies

Jostova 10, 60200 Brno

Czech Republic

\section{Publication Schedule}

Four issues per year: two regular issues (in July and December) plus two special issues (between regular issues) 


\begin{abstract}
About authors
Kristian Daneback, Ph.D. is the Professor of Social Work at the University of Gothenburg, Sweden and in the Faculty of Social Studies at Masaryk University in Brno, Czech Republic. His main field of research is sexuality and in particular internet sexuality, but he is also interested in other internet related phenomena such as parenthood and the internet, cyberbullying, and how the internet can be used to collect qualitative and quantitative data. Daneback has published his research in several well known international journals such as Archives of Sexual Behavior, Cyberpsychology, Behavior, \& Social Networking, Journal of Sexual and Relationship Therapy, Journal of Bisexuality, and Sexual Addiction \& Compulsivity. In addition, he is a reviewer for journals such as Journal of Sex Research, Journal of Computer Mediated Communication, Pediatrics, Sex Roles, and Sexual Reproduction \& Health Care. Currently he serves as the Associated Editor of Cyberpsychology: Journal of Psychosocial Research on Cyberspace and is a Board Member of the Open Journal of Communication and ISRN Family Medicine. Daneback is also a member of the International Academy of Sex Research and the Association of Internet Researchers.
\end{abstract}

Lenka Dedkova, Ph.D., is a researcher at the Institute for Research of Children, Youth and Family (Masaryk university, Brno, Czech republic) and a member of Interdisciplinary Research Team on Internet and Society (IRTIS) which researches social-psychological implications of the internet and technology. Her research interests include cyberbullying and meeting online strangers, with focus on children and adolescents, but she's also interested in online security behavior and social networking sites. Lenka also works as managing editor of Cyberpsychology: Journal of Psychosocial Research on Cyberspace.

David Smahel, Ph.D. is the Professor at the Institute of Children, Youth and Family Research, Masaryk University, the Czech Republic. He is member of Interdisciplinary Research Team on Internet and Society (IRTIS) which researches social-psychological implications of the internet and technology. Current research focuses on adolescents' and adults' internet use, the online risks of children and adolescents, the construction of online identities and virtual relationships, and online addictive behavior. He is editor of Cyberpsychology: Journal of Psychosocial Research on Cyberspace and has co-authored book Digital Youth: The Role of Media in Development (Springer, 2011). Smahel also published in several international journals such as Developmental Psychology, Cyberpsychology \& Behavior, Zeitschrift für Psychologie, European Journal of Developmental Psychology and others. He is also author of several book chapters, such as in Encyclopedia of Cyber Behavior, Encyclopedia of Adolescence, Internet Addiction: A Handbook and Guide to Evaluation and Treatment, Gesundheit und Neue Medien etc. 